\title{
Avaliação do uso de biocomposto de lodo de esgoto como substrato para produção de mudas, 2010.
}

\author{
Evaluation of the use of biocompound of sewage sludge as substrate for seedlings production, 2010. \\ Renata Xavier Alberico Freitas', Geraldo Aclécio Melo² \\ 'Universidade Estadual de Montes Claros \\ 2 Universidade Estadual de Montes Claros
}

\section{Resumo}

O presente trabalho teve como objetivo avaliar o uso de biocomposto à base de lodo de esgoto na produção de mudas, em que foi selecionado o tomateiro Solanum lycopersicum (cv. Santa Adélia) para execução dos experimentos. Inicialmente, foi realizada análise química do biocomposto e misturas, assim como do substrato comercial e do solo combinado com substrato orgânico comumente utilizado (esterco curtido). O delineamento utilizado foi o inteiramente casualizado, com cinco tratamentos e quatro repetições. Utilizaram-se como tratamentos: 1 - Mistura de solo + Esterco bovino curtido (proporção 3:1); 2 - Mistura de solo + composto (proporção 3:1); 3 -Mistura de solo + composto (proporção 2:2); 4 - composto puro; 5 - substrato comercial Plantimax ${ }^{\circledR}$ puro. Foram feitas avaliações morfológicas: altura da planta; diâmetro do caule; número de folhas; massa seca da parte aérea aos 15, 30 e 45 dias após o plantio. Com as doses utilizadas, não foi possível estimar a quantidade adequada de biocomposto para o máximo desenvolvimento das mudas, mas o uso do biocomposto favoreceu o crescimento das plantas. $\mathrm{O}$ tratamento 5 proporcionou o menor desenvolvimento dentre os tratamentos. $\mathrm{O}$ tratamento com $100 \%$ de biocomposto proporcionou a melhor média dos atributos morfológicos avaliados, e o aumento da dose do composto, tratamentos 2 - Solo + composto (proporção 3:1); 3 - Solo + composto (proporção 2:2) até o tratamento 4 - composto (proporção 0: 4) proporcionou um aumento na qualidade de desenvolvimento das mudas. Os resultados foram significativos e estatisticamente diferentes entre si, quanto ao número de folhas, diâmetro, altura e massa seca.

Palavras Chave: lodo de esgoto, compostagem, biofertilizante.

\begin{abstract}
This study aimed to evaluate the use of biocompound based on sewage sludge in the production of seedlings, which was selected in the tomato Solanum lycopersicum (cv. Santa Adélia) for execution of the experiments. Initially, it was performed a chemical analysis of biocompound and mixtures, as well as the substratum and soil combined with commonly used organic substrate (manure tanned). The design was a completely random; with five treatments and four replications. There were used as treatments: 1 - Mixture of soil + cattle manure (3:1), 2 - soil + compost mixture (3:1), 3 - mixture soil + compost (ratio 2:2); 4 - pure compound, 5 - Plantimax ${ }^{\circledR}$ pure commercial substrate. Morphological evaluations were made: plant height, stem diameter, leaf number, and shoot dry mass at 15, 30 and 45 days after planting. With the used doses was not possible to estimate the proper amount of biocompound for maximum development of seedlings, but the use of biocompound favored the growth of plants. Treatment 5 gave the lowest development among the treatments. Treatment with $100 \%$ biocompound provided the best average of the morphological attributes evaluated, and larger doses of the compound: treatments 2 - Soil + compost (3:1), 3 - Soil + compost (ratio 2:2) to treatment 4 - compound (ratio $0: 4$ ), provided an increase in quality of plant development. The results were statistically significant and different from each other regarding the number of leaves, diameter, height and dry weight.
\end{abstract}

Keywords: sewage sludge, composting, bio-fertilizer. 


\section{INTRODUÇÃO}

Os problemas de poluição e degradação ambiental agravaram-se com a formação dos centros urbanos e, com a Revolução Industrial, no final do século XVIII, durante a qual se intensificou a produção de resíduos, devido à mecanização dos processos de produção (LEITE, 1995 apud DIAS, 2000). Naquela época a disposição e o tratamento destes resíduos eram bastante precários. Da mesma forma, a aceleração dos processos industriais, principalmente, no século XX, gerou os chamados poluentes ambientais, decorrentes da produção e má administração destes resíduos, que se refletem atualmente nas inúmeras áreas contaminadas em todo o mundo (OLIVEIRA et al., 2008).

$\mathrm{Na}$ situação atual, as técnicas largamente empregadas para eliminação de resíduos, oriundos de processos industriais, compreendem a remoção de material contaminado das áreas afetadas, seguida de tratamento químico ou físico dos resíduos, e retorno ao meio ambiente. Os resíduos, que não podem sofrer esse tratamento, são incinerados ou depositados em aterros próprios para esta destinação. Entretanto, tais procedimentos geram outros resíduos e agravam o problema dos aterros, ao passo que a incineração leva à geração de gases tóxicos e transferência de poluentes para a atmosfera. Estes inconvenientes acabam por acentuar outras questões ambientais, tais como contaminação da água e do subsolo, chuva ácida, além do aumento do efeito estufa (OLIVEIRA et al., 2008).

Diante disso o cenário mundial aponta para a implantação de programas ambientalmente sustentáveis e, nessa conjuntura, o uso de tecnologias verdes - como a produção de biofertilizante torna-se popular e recebe grande aceitação pública (OLIVEIRA et al., 2008). O lodo de esgoto, resíduo de Estações de Tratamento de Esgoto (ETE), quando tratado e processado recebe o nome de biossólido e adquire características que permitem sua utilização agrícola como biofertilizante. Possui nutrientes essenciais às plantas, além de alto teor de matéria orgânica e composição variável, o que favorece os sistemas de produção, devido o uso de insumos regionais e de baixo custo (BARBOSA; TAVARES FILHO, 2006; SILVA et al., 2004).

A disposição final do lodo de Estação de Tratamento de Esgoto (ETE) é uma preocupação mundial, em razão do crescente volume produzido (LOPES et al., 2005). As principais alternativas de tratamento e destino final de lodos de esgoto incluem sua disposição em aterros sanitários, incineração, disposição oceânica, e várias formas de disposição no solo, tais como a recuperação de áreas degradadas, uso como fertilizante em grandes culturas, reflorestamento (HOPE, 1986).

A reciclagem agrícola é uma prática bastante utilizada, pois transforma o lodo em um insumo agrícola, contribuindo assim para fechar o ciclo bioquímico dos nutrientes minerais, fornecendo matéria orgânica ao solo, estocando o carbono na forma de compostos estáveis e não liberando $\mathrm{CO} 2$ na atmosfera, que contribui para aumentar o efeito estufa. Este último aspecto da reciclagem agrícola do lodo começa a ganhar cada vez mais importância, pois a produção das emissões de $\mathrm{CO} 2$, como no caso da incineração, atua no sentido de desequilibrar o meio natural (FERNANDES; PIERRO; YAMAMOTO, 1993).

Quando usado como insumo agrícola o biossólido passa a ser fonte de matéria orgânica, micro e macro-nutrientes para o solo. Conferindo ao solo maior capacidade de retenção de água, maior resistência à erosão, com diminuição do uso de fertilizantes minerais e possivelmente propiciando maior resistência das plantas aos fitopatógenos (HOPE, 1986). A utilização agrícola do biossólido pode ser favorecida pela técnica da compostagem, que é um processo de decomposição aeróbica, em que há desprendimento de gás carbônico, água e energia proporcionada pela ação de microrganismos, trata-se de um destino útil para resíduos sólidos. (ROCHA, et al., 2008; PERES; NAUMOFF, 1998). De acordo a FAO Corporate Document Repository (2010) a compostagem representa um processo eficaz na transformação do lodo de esgoto em insumo agrícola.

As condições físicas e químicas adequadas durante o processo de compostagem garantem que o composto orgânico final seja de boa qualidade (PERES; NAUMOFF, 1998). Um produto estabilizado, de coloração escura, em que os compostos orgânicos sofreram mineralização e processos de neo-síntese, assumindo natureza coloidal, denominado composto (MELO; MELO; MELO, 2007). Este composto resultante do processo da compostagem pode ser considerado como um enriquecedor do solo, ou seja, poderá ser aplicado para melhorar as características do mesmo, sem que haja uma contaminação do meio ambiente (BRITO et al., 2003).

Embora em quantidade ainda insuficiente, várias pesquisas conduzidas no país mostram que o lodo é um resíduo com perspectivas favoráveis ao uso no solo para produção de mudas. Para o cultivo de alface, LOPES et al. (2005) demonstraram que o lodo de esgoto apresenta potencial para substituição dos fertilizantes minerais. BARBOSA 
\& TAVARES FILHO (2006) apresentam informações sobre o fornecimento de nutrientes pelo lodo de esgoto, incentivando o uso deste como complemento da adubação, podendo reduzir a utilização de fertilizantes químicos, além de ser uma ótima alternativa na recuperação de áreas.

Existem ainda, informações do aproveitamento do lodo de esgoto em espécies florestais, aonde o lodo vem sendo utilizado com sucesso. GARCIA et al. (2010) apresentam informações sobre o potencial do uso do lodo de esgoto, gerado na ETE do município Jerônimo Monteiro para o cultivo de Eucalyptus. GUERRINI e colaboradores em 2000 propuseram a utilização de substratos à base de biossólido no solo do cerrado, afim de melhorar a fertilidade do solo, a nutrição mineral e a produção, assim como NÓBREGA et al. (2007) confirmam os resultados satisfatórios avaliando o crescimento inicial de AROEIRA (Schinus terebynthifolius Raddi).

A vista do exposto, o trabalho propõe a utilização do lodo de esgoto da estação de tratamento de efluentes juntamente com os resíduos de demais processos de uma indústria farmacêutica de Montes Claros-MG, após compostagem. Neste estudo, foi testada a viabilidade do uso do composto produzido, puro ou em misturas e comparando com substrato comercial e orgânico, comumente utilizado para produção de mudas.

\section{MATERIAIS E MÉTODOS}

\section{Localização e instalação}

$\mathrm{O}$ experimento foi realizado em duas etapas: a primeira etapa consistiu na preparação das amostras com diferentes proporções, seguida da caracterização química do composto orgânico e comercial e das proporções preparadas, realizada no Laboratório de análises de solo da UFMG Núcleo de Ciências Agrárias; a segunda etapa foi feita na área experimental do Departamento de Biologia Geral da Universidade Estadual de Montes Claros (Unimontes) - Campus Darcy Ribeiro, onde foram testados os substratos para a produção de mudas de tomateiro.

\section{Procedência e preparo dos substratos}

O composto usado no experimento foi disponibilizado pela empresa farmacêutica $X$ localizada no município de Montes Claros-MG. O lodo de esgoto (principal componente do composto) foi gerado pela Estação de Tratamento de Esgoto instalada na própria empresa, que se destina ao tratamento dos resíduos sanitários e industriais, e posteriormente foi agregado a demais resíduos gerados pela empresa: restos alimentares, palha (poda de plantas) e ajuda filtrante (pó de coloração clara, fino e limpo, solto, com partículas de forma irregular, apresentando um número considerável de espículas diatomáceas quando observado ao microscópio), produzindo o composto pela técnica da compostagem desenvolvida pela empresa. O composto foi coletado na empresa após fase de estabilização (120 dias).

O solo utilizado é argiloso (terra de barranco) coletado em área de corte dentro da área urbana de Montes Claros-MG. O esterco bovino curtido foi obtido em propriedade rural próximo à cidade de Montes Claros, e o substrato comercial, plantmax ${ }^{\circledR}$ foi obtido no comércio local.

O composto, o solo e o esterco bovino foram peneirados e foram preparados nas seguintes proporções que constituíram os tratamentos utilizados: 1 - Mistura de solo + Esterco bovino curtido (proporção 3:1); 2 - Mistura de solo + composto (proporção 3:1); 3 -Mistura de solo + composto (proporção 2:2); 4 - composto puro; 5 - Plantimax ${ }^{\circledR}$ puro. Até uso os substratos foram acondicionados em baldes de plástico com tampa..

\section{ANÁLISE QUÍMICA DOS TRATAMENTOS E AVALIAÇÃO DE CORROSIDADE, REA- TIVIDADE E TOXICIDADE DO LODO DE ESGOTO}

Cada substrato foi homogeneizado e foram retiradas amostras que foram levadas ao Laboratório de análises de solo da UFMG para análise química

Os dados de Corossividade, Reatividade e Toxicidade (parâmetros inorgânicos e orgânicos) foram obtidos a partir de análises realizadas por SGS GEOSOL Laboratórios Ltda, que foram feitas para o lodo de esgoto, que representa o principal componente do composto em questão.

\section{Avaliação do biocomposto como substrato para produção das mudas}

Foi escolhido para testar a viabilidade do composto o tomateiro Solanum lycopersicum (cv. Santa Adélia), que é uma planta bastante exigente em nutrientes e tem como prática no sistema produtivo, o pré-plantio para produção de mudas.

\section{Instalação do experimento}

$\mathrm{O}$ experimento foi montado em bandejas de poliestireno de 128 células, que foram preenchidas com os substratos. Na semeadura foram abertos orifícios de $5 \mathrm{~mm}$ de profundidade e semeadas três 
sementes por célula. Durante todo período foram feiras irrigações diárias e as bandejas foram suspensas $0,30 \mathrm{~m}$ do solo o que facilitou a lixiviação do excesso de água. Após 7 dias de plantio foi feito desbaste deixando-se somente uma plântula por célula.

\section{Delineamento experimental}

Os tratamentos foram individualizados nas bandejas, com disposição aleatória dos 5 tratamentos: 1 - Mistura de solo + Esterco bovino curtido (proporção 3:1); 2 - Mistura de solo + composto (proporção 3:1); 3 - Mistura de solo + composto (proporção 2:2); 4 - composto puro; 5 - Plantimax ${ }^{\circledR}$ puro. Cada repetição foi composta por 16 plantas.

\section{Atributos morfológicos avaliados}

Foram feitas medidas de: altura - medida com o auxílio de uma régua graduada em centímetros, do nível do substrato até a parte mais alta da planta; diâmetro - medido com auxílio de paquímetro digital; número de folhas por planta - obtido através da contagem direta das folhas emitidas pelas plantas. Os parâmetros foram avaliados por 45 dias a cada 15 dias a partir do plantio, totalizando três medições. Também foi avaliada a massa seca da parte aérea, onde ao fim dos 45 dias as mudas foram retiradas, cortadas ao nível do substrato, e colocadas para secar em estufa com circulação de ar até peso constante. Para esta avaliação foram consideradas todas as mudas desenvolvidas que constituíram cada tratamento nas bandejas ao final de 45 dias (vide tabela 2).

\section{Análise estatística}

Foi realizada análise de variância - ANOVA DE CRITÉRIO ÚNICO, utilizando o software Minitab 16. Na análise, foi verificado se as médias de altura, número de folhas e massa seca eram iguais entre si (possuem mesma média populacional), bem como se a média populacional para massa seca, ao término do estudo (45 dias), era diferente dentre os tratamentos.

\section{RESULTADOS E DISCUSSÃO}

\section{Composição química dos substratos}

A utilização do lodo de esgoto para uso agrícola é normatizada por lei, prescrita pela resolução $n^{\circ}$. 375/2006 do conselho Nacional do Meio Ambiente - CONAMA (BRASIL, 2006), que estabelece critérios e procedimentos para o uso agrícola de lodos de esgoto gerados em estações de tratamento de esgoto. A Associação Brasileira de Normas Técnicas ABNT NBR 10004 (2004) estabelece uma classificação para resíduos sólidos, que os dividem em duas classes, podendo ser enquadrados como classe I considerados perigosos e classe II não perigosos, para esta segunda definição são divididos em inertes (B) e não inertes (A).

O Lodo da ETE, utilizado para produção do composto aqui utilizado, de acordo com o Relatório Técnico de Classificação de Resíduos Sólidos ABNT NBR 10.004:2004 é classificado como Classe II A (Não Perigoso - Não Inerte) (Relatório Técnico de Classificação de Resíduos Sólidos ABNT NBR 10.004:2004). Também não é Corrosivo, por não apresentar características corrosivas e não é Reativo, por não apresentar características reativas. Quanto à toxicidade avaliada pelos parâmetros analisados: Classificação de toxicidade por lixiviação - Parâmetros Inorgânicos; Classificação de toxicidade por lixiviação - Parâmetros Orgânicos (Pesticidas); Classificação de toxicidade por lixiviação - Parâmetros Orgânicos (Outros Orgânicos); Classificação de toxicidade por solubilização - Parâmetros Orgânicos (Cromatografia) apresentaram resultados conforme especificação, de acordo o Relatório Técnico de Classificação de Resíduos Sólidos ABNT NBR 10.004:2004. Dentro da classificação de toxicidade por solubilização, o lodo de esgoto apresentou-se teores de Cloreto e Sódio acima do limite máximo permitido.

De acordo LAKHDAR et al. (2010) a matéria orgânica controla os efeitos do sal nos solos. Dessa forma os altos teores de Cloreto e Sódio no lodo de esgoto, podem ter sido controlados pelos resíduos alimentares e a palha (fonte de matéria orgânica) que foram misturados ao lodo de esgoto no processo da compostagem. As plantas não apresentaram características desfavoráveis relacionadas a este parâmetro.

A composição química de amostras dos substratos utilizados nos tratamentos, considerando: 1 - Mistura de solo + Esterco bovino curtido (proporção 3:1); 2 - Mistura de solo + composto (proporção 3:1); 3 - Mistura de solo + composto (proporção 2:2); 4 - composto puro; 5 - Plantimax ${ }^{\circledR}$ puro é apresentada na tabela 1.

Observa-se que todos os substratos apresentaram acidez fraca a média. Conforme MENGEL, K. e KIRKBY, E.A. (1987) para substratos orgânicos a faixa desejável de $\mathrm{pH}$ é 5,0 a 5,5 , em que há maior disponibilidade de nutrientes às plantas, em $\mathrm{pH}$ alto não há total disponibilidade dos nutrientes. No caso de compostos de lodo de esgoto, de acordo RICC e colaboradores (2010), ocorre aumento da basicidade do composto à 
Tabela 1. Composição química de amostras dos substratos utilizados: 1 - Mistura de solo + Esterco bovino curtido (proporção 3:1); 2 - Mistura de solo + composto (proporção 3:1); 3 - Mistura de solo + composto (proporção 2:2); 4 - composto puro; 5 - Plantimax ${ }^{\circledR}$ puro.

\begin{tabular}{|c|c|c|c|c|c|c|c|c|c|c|}
\hline \multirow{2}{*}{ Atributos do solo } & \multicolumn{10}{|c|}{ Amostras } \\
\hline & 1 & Nível & 2 & Nível & 3 & Nível & 4 & Nível & 5 & Nível \\
\hline pH em água & 6,7 & A & 6,1 & A & 6,4 & A & 6,5 & A & 5,8 & B \\
\hline P Mehlich $\left(\mathrm{mg} \mathrm{Kg}^{-1}\right)$ & 330,0 & MB & 690 & MB & 1560 & MB & 2040 & MB & 750,0 & MB \\
\hline $\mathrm{P}$ remanescente ( $\mathrm{mg} \mathrm{L}^{-1}$ ) & 31,74 & - & 31,74 & - & 42,34 & - & 44,30 & - & 37,55 & - \\
\hline $\mathrm{K}\left(\mathrm{mg} \mathrm{Kg}^{-1}\right)$ & 440 & MB & 290 & MB & 480 & MB & 660 & MB & 580 & MB \\
\hline $\mathrm{Ca}\left(\mathrm{cmolc} \mathrm{dm}^{-3}\right)$ & 6,70 & MB & 5,50 & MB & 9,10 & MB & 7,5 & MB & 14,8 & MB \\
\hline $\mathrm{Mg}\left(\mathrm{cmolc} \mathrm{dm}^{-3}\right)$ & 2,80 & MB & 1,70 & MB & 1,50 & B & 1,4 & B & 10,20 & MB \\
\hline $\mathrm{H}+\mathrm{Al}\left(\mathrm{cmolc} \mathrm{dm}^{-3}\right)$ & 1,55 & Bx & 1,54 & Bx & 1,07 & Bx & 0,85 & MBx & 0,81 & MBx \\
\hline $\mathrm{SB}\left(\mathrm{cmolc} \mathrm{dm}^{-3}\right)$ & 10,63 & MB & 7,94 & MB & 11,83 & MB & 10,59 & MB & 26,49 & MB \\
\hline $\mathrm{t}\left(\mathrm{cmolc} \mathrm{dm}^{-3}\right)$ & 10,63 & MB & 7,94 & B & 11,83 & MB & 10,59 & MB & 26,49 & MB \\
\hline $\mathrm{T}\left(\mathrm{cmolc} \mathrm{dm}^{-3}\right)$ & 12,18 & B & 9,48 & B & 12,90 & B & 11,45 & B & 27,29 & MB \\
\hline V (\%) & 87 & MB & 84 & MB & 92 & MB & 93 & MB & 97 & MB \\
\hline Mat. Org. (dag Kg-1) & 5,58 & B & 2,12 & M & 3,39 & M & 6,22 & B & 17,44 & MB \\
\hline
\end{tabular}

$\mathrm{MBx}=$ muito baixo; $\mathrm{Bx}=$ baixo; $\mathrm{B}$ : bom; $\mathrm{M}=$ médio; $\mathrm{A}=$ alto; $\mathrm{MB}=$ muito bom. $\mathrm{MBx}=$ muito baixo; $\mathrm{Bx}=$ baixo; $\mathrm{B}$ : bom; $\mathrm{M}=$ médio; $\mathrm{A}=$ alto; $\mathrm{MB}=$ muito bom.

medida que aumenta a estabilização do mesmo, pois no processo de compostagem ocorre a formação de ácidos que contribuem para que o início o composto apresente caráter ácido. Observa-se também que o composto é fonte de importantes nutrientes, apresentado níveis bons ou muito bons. Os níveis de fósforo e o potássio, macronutrientes, foram destaques no tratamento 4 - composto puro.

Houve uma tendência ao aumento da matéria orgânica com o aumento da quantidade o composto nas proporções, com nível bom no composto puro, indicando ser também uma boa fonte de matéria orgânica. A matéria orgânica proporciona o aumento da agregação, da macroporosidade do solo, além de reduzir a densidade, que propicia uma maior capacidade de retenção de água (ALVES; CAMPOS, 2008). O substrato comercial plantmax ${ }^{\circledR}$ apresentou-se também com níveis satisfatórios na análise química.

\section{CRESCIMENTO DAS MUDAS}

A figura 1 apresenta o desenvolvimento das mudas de tomate nos diferentes tratamentos. As indicações por setas representam as mudas desenvolvidas no tratamento 4 (somente composto), que apresentaram o melhor desenvolvimento.

Aos 15 dias não houve diferença entre os tratamentos para altura das plantas, diâmetro do colo e número de folhas (figura 2). Aos 30 e 45 dias observa-se diferença significativa com superioridade dos demais tratamentos em relação ao substrato comercial. Entre os tratamentos contendo o composto, apesar de não ter ocorrido diferença

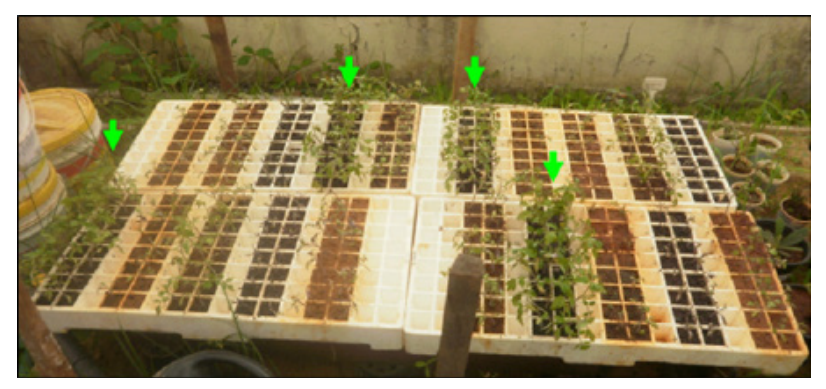

Figura 1. Foto das mudas produzidas aos 45 dias, representando os 5 tratamentos nas 4 repetições.

significativa, observa-se aumento gradativo e proporcional ao aumento da dose do composto no substrato. $\mathrm{O}$ substrato comercial apesar de boa composição química apresentou menor crescimento das mudas. Provavelmente, isso aconteceu devido à rápida liberação dos nutrientes já nos primeiros dias. Este tipo de substrato é indicado somente para a germinação das mudas (SILVA; PEIXOTO; JUNQUEIRA, 2001). Dados deste trabalho suportam essa indicação onde foi observado que não houve diferença entre os tratamentos aos 15 dias após plantio. 
Tratamento $1 \square$ Tratamento $2 \square$ Tratamento $3 \square$ Tratamento $4 \square$ Tratamento 5

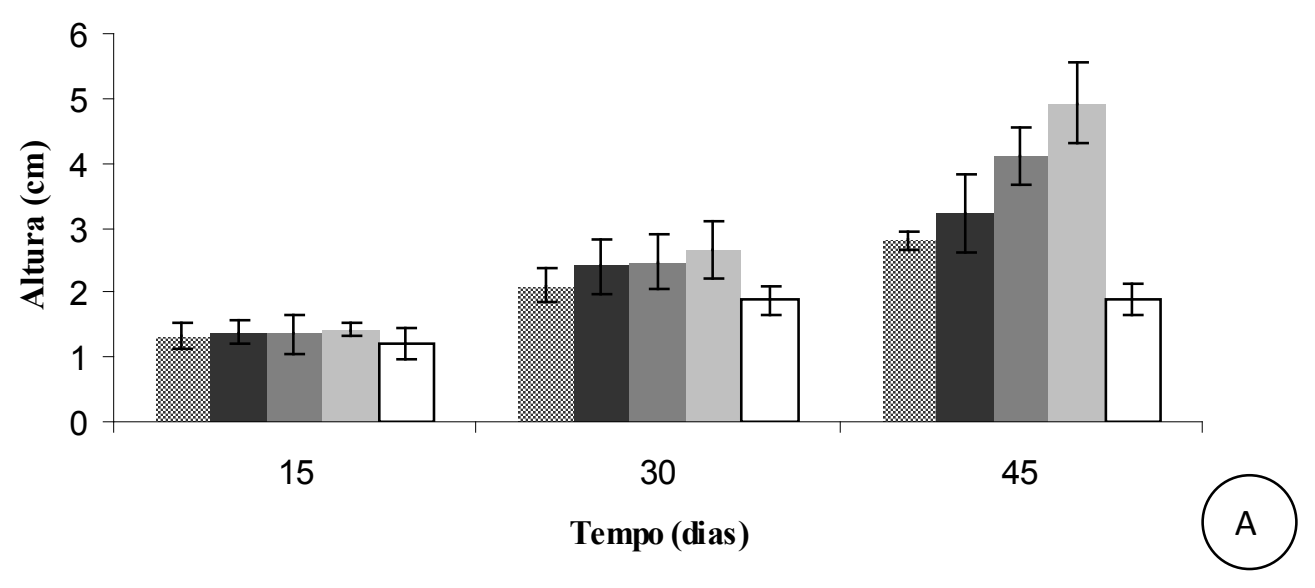

क Tratamento $1 \square$ Tratamento $2 \square$ Tratamento $3 \square$ Tratamento $4 \square$ Tratamento 5

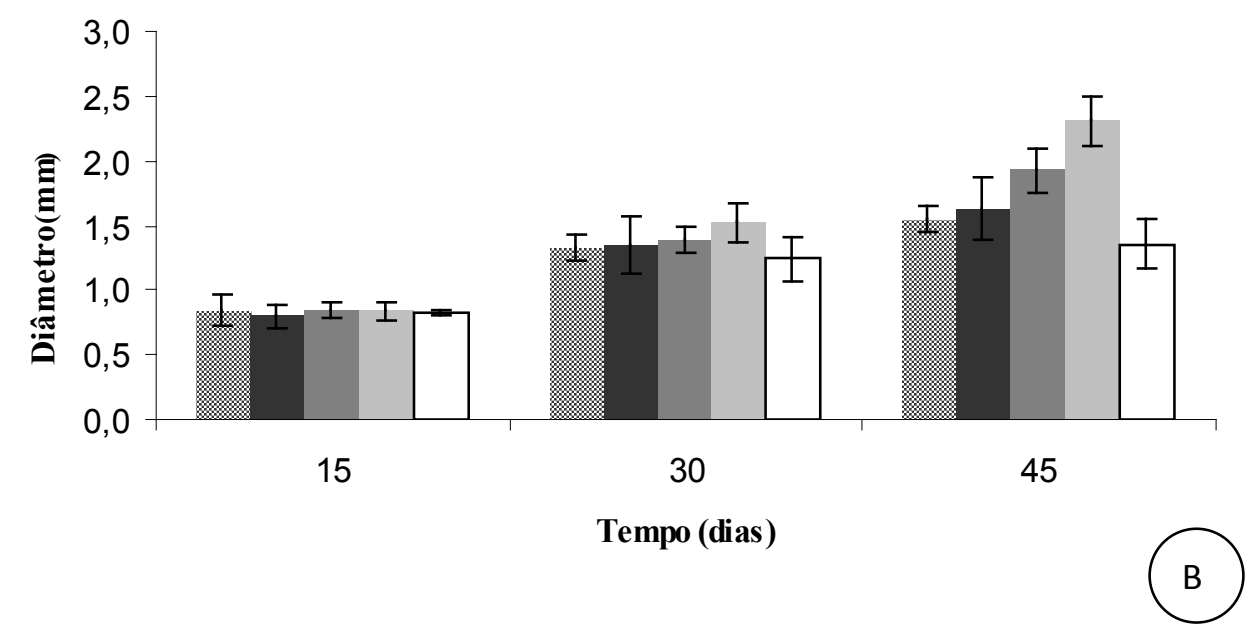

ॠ Tratamento $1 \square$ Tratamento $2 \square$ Tratamento $3 \square$ Tratamento $4 \square$ Tratamento 5

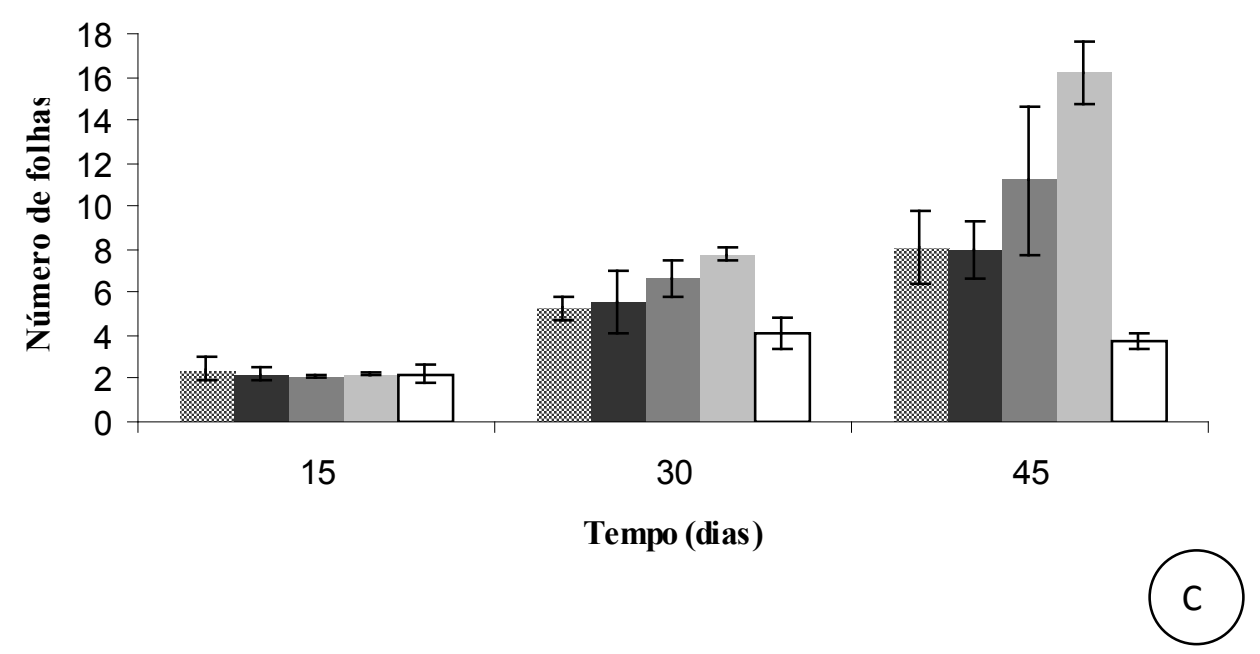

Figura 2. Atributos morfológicos de mudas de tomate crescendo em diferentes substratos. (A) Altura. (B) Diâmetro. (C) Número de folhas. Barras indicam intervalo de confiança para $\alpha=0,005$. 


\section{: Tratamento $1 \square$ Tratamento $2 \square$ Tratamento $3 \square$ Tratamento $4 \square$ Tratamento 5}

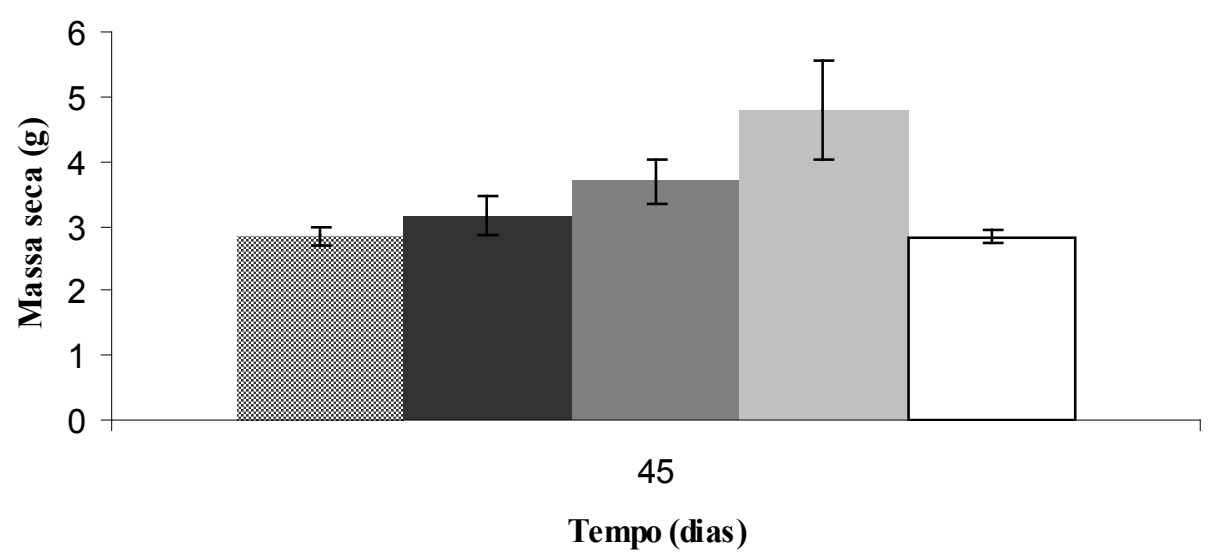

Figura 3. Massa seca média aos 45 dias de plantas de tomate crescendo nos diferentes tratamentos. Barras indicam intervalo de confiança para $\alpha=0,005$.

A massa seca final da parte aérea das plantas foi influenciada pelos diferentes substratos (figura 3). Houve também aumento gradativo com aumento da proporção do composto no substrato e o tratamento 4 (composto puro) foi superior aos demais. Os menores valores foram observados para o substrato comercial.

Para melhor caracterizar o desempenho dos substratos para produção de mudas, foi calculado um índice total, que é o produto da multiplicação de todos os parâmetros avaliados. Dados do índice total são apresentados na figura 4 , onde observa-se que o tratamento 4 (somente composto) foi superior aos demais tratamentos e o menor índice para o substrato comercial. Houve um aumento gradativo do índice à medida que houve um aumento da concentração do composto nos substratos.

Na tabela 2 é apresentado o número final de plantas em cada tratamento. Houve maior mortalidade de plantas nos tratamentos 1 (mistura de solo e esterco bovino - 3:1) e 2 (mistura de solo e composto - 3:1). O menor número de plantas observado para estes tratamentos foi devido à menor germinação (dados não apresentados). A menor germinação pode ter ocorrido devido a maior quantidade de solo nestes tratamentos e como trata-se de um solo argiloso, a compactação pode ter dificultado a emergência das plantas. Com a utilização do composto e suas misturas houve um aumento da aeração dos substratos tornado-os mais leves e isto facilita a emergência da plantas. A melhor aeração também influência sobre a absorção dos nutrientes do solo através da mineralização da matéria orgânica e oxidação de elementos, como o $\mathrm{NH}+4$ que passa à forma de NO-3 (Bonato et al., 1998).

Os resultados foram significativos e estatisticamente diferentes entre si, quanto ao número de folhas, diâmetro, altura e massa seca.

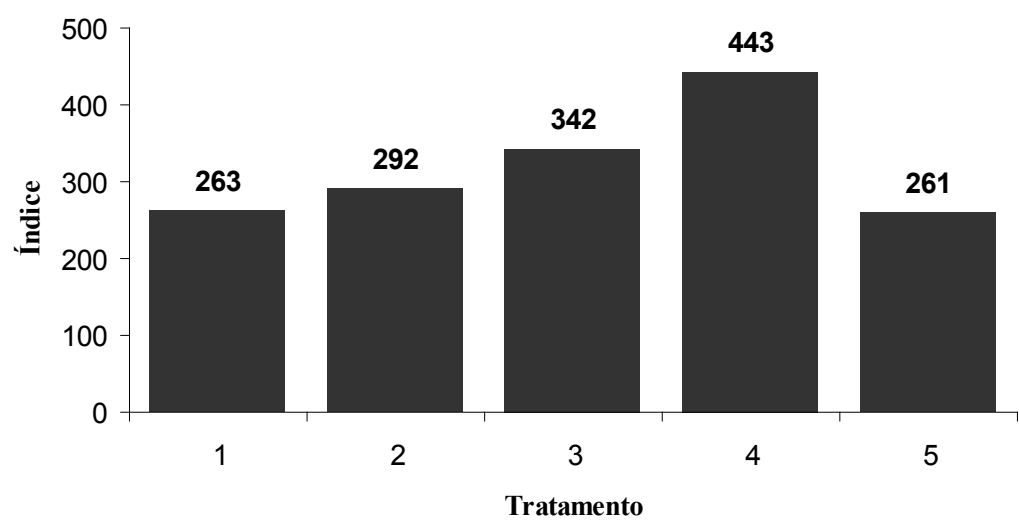

Figura 4. Índice total de crescimento aos 45 dias para plantas de tomate crescendo em diferentes substratos. 
Tabela 2. Número final de plantas de tomate nos diferentes tratamentos em cada bandeja.

\begin{tabular}{|c|c|c|c|c|}
\hline \multirow{2}{*}{ Tratamento } & \multicolumn{4}{|c|}{ Total de mudas } \\
\hline & Bandeja 1 & Bandeja 2 & Bandeja 3 & Bandeja 4 \\
\hline 1 & 8 & 5 & 9 & 5 \\
\hline 2 & 13 & 6 & 15 & 14 \\
\hline 3 & 14 & 14 & 15 & 14 \\
\hline 4 & 14 & 16 & 16 & 16 \\
\hline 5 & 12 & 15 & 16 & 15 \\
\hline
\end{tabular}

\section{CONCLUSÃO}

- O composto produzido pela Estação de Tratamento de Efluentes, da empresa farmacêutica $\mathrm{X}$, localizada em Montes Claros-MG, demonstrou ser um bom substrato para produção de mudas;

- Com as proporções de composto utilizadas não foi possível estimar a quantidade adequada de biocomposto para o máximo desenvolvimento das mudas. Porém houve uma tendência de que com aumento da proporção do biocomposto, um melhor desenvolvimento das mudas, sendo que o biocomposto puro apresentou-se superior em relação aos demais tratamentos;

- Apesar do bom desempenho do composto como substrato para produção de mudas e possivelmente como um biofertilizante, devem-se levar em consideração as concentrações máximas de metais em solos agrícolas e as cargas cumulativas máximas de metais em solos pela aplicação de compostos que contenham lodo de esgoto, afim de concluir que há ou não impacto da sua utilização (ABREU JÚNIOR et al, 2005).

\section{REFERÊNCIAS}

Agricultural use of sewage sludge - FAO Corporate Document Repository, 2010. Disponível em: http: // www.fao.org. Acesso em: 11 de Dezembro de 2010.

ALVES, M.C; CAMPOS, F.S. Uso do lodo de esgoto na reestruturação de solo degradado. Revista Brasileira Ciência do Solo, v.32, p.1389-1397, 2008.

\section{BARBOSA, G. M. C. TAVARES FILHO, J. Uso} agrícola do biossólido: influência nas propriedades químicas e físicas do solo, produtividade e recuperação de áreas degradadas. Semina: Ciências Agrárias, v.27, n.04, p. 565-580, 2006.

BONATO, C. M.; RUBIN FILHO, C. J.; MELGES, E.; SANTOS, V. D. Nutrição mineral de hortaliças Maringá, 1998. Disponível em: http://www.dbi.uem. br/aposti1.pdf. Acesso em: 20 de Junho de 2010.

BRASIL. Ministério do Meio Ambiente, Conselho Nacional de Meio Ambiente, CONAMA.

Resolução CONAMA n ${ }^{\circ} .375 / 2006$, de 30 de agosto de 2006 - In: Resoluções, 2006.

Disponível em: http://www.mma.gov.br. Acesso em: 09 de Setembro de 2010.

BRITO, N. N.; BRANDÃO, T. C. O.; CONEGLIAN, C. M. R.; SOBRINHO, G. D.; TONSO, S.; PELEGRINI, R. Compostagem. IV Fórum de Estudos Contábeis, Faculdades Integradas Claretianas, Rio Claro, SP, 2003.

DIAS, A. E. X. O. Biorremediação de áreas afetadas por resíduos sólidos tóxicos. In: SISINNO, C. L. S.; OLIVEIRA, R. M. (Org.) Resíduos Sólidos, Ambiente e Saúde: uma visão multidisciplinar. Rio de Janeiro: Editora Fiocruz, 142 p., 2000.

FERNANDES, F; PIERRO. A.C; YAMAMOTO R. Y. Produção de fertilizante orgânico por compostagem do lodo gerado por estações de tratamento de esgotos. Pesquisa Agropecuária Brasileira, v.28, n.5, 1993.

GARCIA, G.O; GONÇALVES I.Z; MADALÃO J.C; NAZÁRIO, A.A; REIS, E.F. Crescimento de mudas de eucalipto submetidas à aplicação de biossólidos. Revista Ciência Agronômica, v.41, n.1, p.87-94, Fortaleza. CE, 2010.

GUERRINI, I.A.; VILLAS BÔAS, R.L.; BENEDETTI, V.; COMÉRIO, J.; MORO, L.; Application of Wood ash and pulp and paper sludge to Eucalyptus grandis in three Brazilian soils. In: Principles and practice of residuals use. Seattle: College of Forest Resources, University of Washington, 2000. p.127131.

HOPE, J. Sewage Sludge Disposal and Utilization 
Study. Washington State Institute for Public Policy, 1986. Disponível em: http://www.wsipp.wa.gov/ rptfiles/sewage.pdf. Acesso em: 11 de Novembro de 2010.

ABREU JÚNIOR, C.H.; BOARETTO, A.E; MURAOKA, T; KIEHL J.C. Uso agrícola de resíduos orgânicos potencialmente poluentes: propriedades químicas do solo e produção vegetal. In: Tópicos Ciências do Solo, 4: 391-470, 2005.

LAKHDAR, A; SCELZA, R; SCOTTI, R; RAO, M.A; JEDIDI, N; GIANFREDA, L; ABDELLY, C. The effect of compost and sewage sludge on Soil biologic activities in salt affected soil. Revista de la ciencia del suelo y nutrición vegetal 10(1): 40 - 47, 2010.

LOPES, J.C; RIBEIRO, L.G; ARAÚJO, M.G; BERALDO, M.R.B.S. Produção de alface com doses de lodo de esgoto. UFES, CCA, Depto. Fitotecnia, Revista brasileira de Horticultura, v. 23, Alegre-ES, 2005.

MELO, G. M. P.; MELO, V. P. de.; MELO, W. J. de. Compostagem. Jaboticabal, Faculdade de Ciências Agrárias e Veterinárias, 2007. 10p. Disponível em: $<$ www.ambientenet.eng.br > Acesso em: 01 de ago. 2010.

MENGEL, K.; KIRKBY, E.A. Principles of plant nutrition. Bern, International Potash Institute, 1987. $687 \mathrm{p}$.

NÓBREGA, R. S. A; VILAS BOAS, R. C; NÓBREGA, J. C. A; DE PAULA, A. M; MOREIRA, F.M.S. Utilização de biossólido no crescimento inicial de mudas de aroeira (Schinus terebynthifolius Raddi). Revista Árvore, v.31, n.2, Viçosa, 2007.

OLIVEIRA, S. de. ; LEMOS, J. L. S.; BARROS, C. A.; LEITE, S. G. F. Emprego de Fungos Filamentosos na Biorremediação de Solos Contaminados por Petróleo: Estado da Arte. Série tecnologia ambiental. ISSN 0103-7374. Rio de Janeiro: CETEM/MCT, 67p., 2008.

PERES, C. S.; NAUMOFF, A. F. Destinação de resíduos sólidos urbanos: o processo de compostagem. In: SOARES, C. H. L. (Ed.) II Reunião Nacional de Microbiologia Aplicada, 1998. Florianópolis: Universidade de Santa Catarina, v. 2. Disponível em: http://www.ufsc.br/ccb/PDF/c7.PDF.
Relatório Técnico de Classificação de Resíduos Sólidos ABNT NBR 10.004:2004.

RICCI, A.B; PADOVANI, V.C. R; JÚNIOR, R.P. Uso de lodo de esgoto estabilizado em um solo decapitado. II - Atributos químicos e revegetação. Revista Brasileira Ciências do Solo 34: 543-551, 2010.

ROCHA, C. O; RIBEIRO, G. N; GADELHA, A. S.; BARROS, D.F. Utilização da compostagem no tratamento de resíduos sólidos e seus benefícios para o meio ambiente. REBAGA (Mossoró- RN - Brasil), v.2, n.1, p.01-05, 2008.

SILVA, R.P; PEIXOTO, J.R; JUNQUEIRA, N.T.V. Influência de diversos substratos no desenvolvimento de mudas de maracujazeiro azedo (Passiflora edulis Sims f. flavicarpa DEG). Revista. Brasileira de. Fruticultura [online]. 2001, vol.23, n.2, pp. 377-381. ISSN 0100-2945.

SILVA, W.T. C; SALLES, L.C; NOVAES, A.P; NETO, L.M; MILORI, D.M.B.P; SIMÕES, M.L; HANEDA, R.N; FIALH, L.L. Potencialidade do uso de composto produzido a partir de lodo de esgoto urbano e poda verde de àrvore. Circular técnica - 25. EMBRAPA. São Paulo, Dezembro, 2004 